\title{
INCLUSÃO SUBORDINADA DE ASSENTAMENTOS RURAIS À CADEIA PRODUTIVA DO LEITE NO ESTADO DE GOIÁS
}

Sheila Marli de Melo Rezende

Universidade Federal do Maranhão (UFMA)

Dinalva Donizete Ribeiro

Universidade Federal de Goiás (UFG)

\section{INCLUSÃO SUBORDINADA DE ASSENTAMENTOS RURAIS À CADEIA PRODUTIVA DO LEITE NO ESTADO DE GOIÁS}

Resumo: A produção do leite é uma das atividades mais presentes em assentamentos rurais, pois desempenha um importante papel na geração de emprego e renda. Os dados e reflexões aqui apresentados fazem parte da dissertação de mestrado desenvolvida sobre a comercialização do leite em dois assentamentos rurais no noroeste goiano. A pesquisa se apoiou na revisão bibliográfica, na pesquisa documental e na pesquisa de campo, e considera, apenas, 23 famílias que mantêm a atividade leiteira como a principal atividade econômica do lote. (Conclui-se). Ressalta que a atividade leiteira é uma das estratégias de reprodução econômica e social das famílias assentadas. Conclui, no entanto, que os resultados da pesquisa apontaram para a reprodução do processo de subordinação da renda da terra das famílias assentadas à cadeia produtiva do leite, tendo em vista que a atividade leiteira não tem autonomia e domínio sobre sua renda, pois a parcela maior do lucro fica em poder dos laticínios.

Palavras-chave: Produção e comercialização do leite, assentamentos rurais, inclusão subordinada.

\section{SUBORDINATED INCLUSION OF RURAL SETTLEMENTS TO THE MILK PRODUCTION CHAIN IN THE STATE OF GOIÁS}

Abstract: Dairy production is one of the most ubiquitous activities in rural settlements, since it develops an important role as source of employment and income areas. The data and observations presented in this paper are part of a master dissertation about dairy marketing in two rural settlements in Goias' northwest region of Brazil. This research is based on bibliographic and documental reviews plus a field research. There were considered 23 families that have dairy production as their primary economic activity. It was concluded that dairy production is one of the strategies used for economic and social reproduction of the settled families. However, the results of this research point to the settled families' land income subordination to the dairy productive chain, as it isn't autonomous and does not possess domain over its income generation, since most of the profit remains with the dairy industries.

Key words: Milk production and commercialization, rural settlements, subordinated inclusion.

Recebido em: 09.12.2014 Aprovado em: 15.01.2015. 


\section{INTRODUÇÃO}

Os assentamentos rurais são considerados como espaços de reprodução social pautados nas ações de políticas públicas de acesso à terra visando 0 desenvolvimento rural. 0 acesso à terra, via assentamento, proporciona certa emancipação econômica e inserção cidadã, mesmo considerando, em alguns casos, as limitações de crédito, a precária assistência técnica e o difícil acesso ao mercado (MOREIRA, 1999; PAULINO, 2010).

As discussões aqui apresentadas compõem a dissertação de mestrado intitulada Comercialização do leite dos Assentamentos Carlos Mariguela e Luiz Ório no município de Itaberaí - GO: análise comparativa, desenvolvida no Programa de Pós-Graduação em Agronegócio (PPAgro) da Escola de Agronomia da Universidade Federal de Goiás (UFG) e defendida em 25 de abril de 20141.

Aatividade leiteira é uma das estratégias de reprodução econômica e social nos assentamentos rurais pesquisados, pois desempenha um importante papel na geração de emprego e renda. Todavia, a inserção dessas famílias na cadeia produtiva do leite no município de Itaberaí, que foi selecionado como estudo de caso, se dá de forma subordinada ao capital, tendo em vista que a atividade leiteira não tem autonomia e domínio sobre sua renda, pois a parcela maior do lucro fica em poder dos laticínios, que representam o capital industrial à jusante desse segmento produtivo.

Isso permite a reflexão sobre a importância das políticas públicas que garantam a continuidade da agricultura familiar e a reprodução do campesinato no espaço rural. Além disso, é importante repensar a forma de fazer agricultura nos assentamentos rurais, buscando a agregação de valor do produto comercializado, por meio do beneficiamento da produção, com a constituição de agroindústrias familiares e de cooperativas que garantam o acesso a novos mercados. Essas ações permitiriam, assim, a apropriação maior da renda da terra, ao invés da simples transferência para o capital.
A pesquisa se apoiou na análise comparativa de dois assentamentos: Luiz Ório, vinculado à Federação dos Trabalhadores do Estado de Goiás (FETAEG) e Carlos Mariguela, vinculado ao Movimento dos Trabalhadores Rurais Sem-Terra (MST), ambos localizados no município de Itaberaí - GO. A escolha de um assentamento vinculado ao MST parte do pressuposto de que ele pode possuir aspectos diferentes na sua organização e de que ele pode gerar resultados distintos de assentamentos vinculados a outros movimentos e organizações. Já a escolha de outro assentamento, vinculado à FETAEG, se justifica pela atuação desta instituição no estado de Goiás: desde a sua fundação na década de 1970, coordena e defende os interesses dos trabalhadores e pequenos proprietários rurais goianos.

O objetivo principal da pesquisa desenvolvida no mestrado foi analisar de que forma o grau de organização social, política, econômica e tecnológica das famílias dos Assentamentos Carlos Mariguela (MST) e Luiz Ório (FETAEG), localizados no município de Itaberaí, contribui para inserção delas no mercado do leite.

O município de Itaberaí dista $89 \mathrm{~km}$ de Goiânia, atual capital do estado de Goiás. Possui área total de $1.457 \mathrm{~km}^{2}$ e população de 35.371 habitantes. As principais vias de acesso são as rodovias GO 070 e GO 156. Está localizado no bioma cerrado e faz parte da bacia hidrográfica do Tocantins (INSTITUTO BRASILEIRO DE GEOGRAFIA E ESTATÍSTICA, 2010).

O município se destaca na pecuária de corte e de leite, na avicultura, na produção de soja, milho, feijão, tomate, goiaba, cana-de-açúcar e laranja. 0 cultivo florestal, como o eucalipto, encontra-se em franca expansão para atender à produção de lenha $\mathrm{e}$ carvão vegetal (MEDINA; CAMARGO, [20--?]).

Quanto à presença de agroindústrias, 0 município possui laticínios e frigoríicos. 0 setor de comércio e serviços tem uma expressiva participação na composição do Produto Interno Bruto (PIB) do município, incluindo rede bancária, hoteleira e hospitalar, além de uma unidade da Universidade Estadual de Goiás (UEG) e do comércio, em geral, visando atender as necessidades da população. 
Figura 1 - Município de Itaberaí - GO

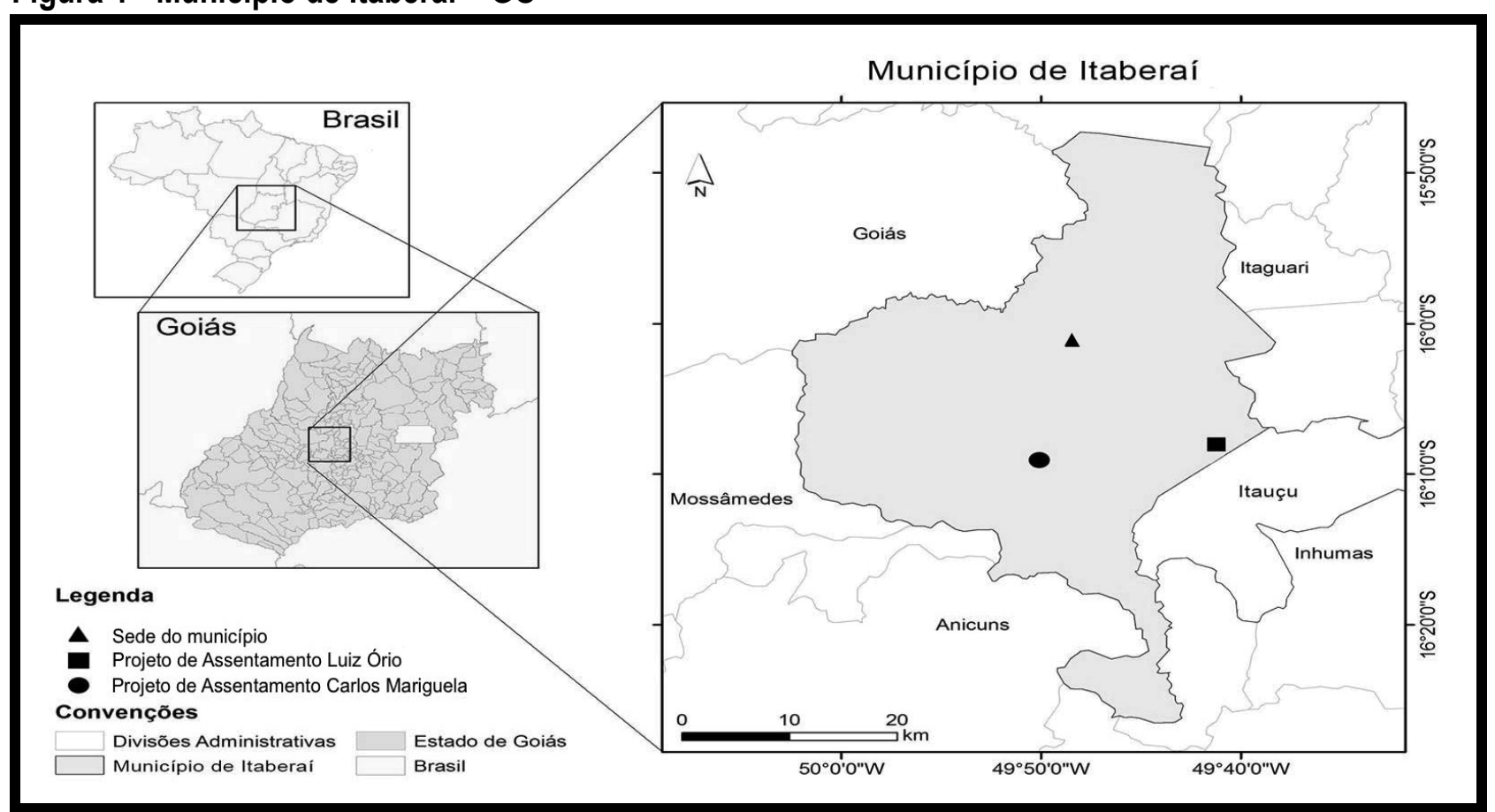

Fonte: INSTITUTO NACIONAL DE COLONIZAÇÃO E REFORMAAGRÁRIA. Shape dos Assentamentos. [mensagem pessoal]. Mensagem recebida por<sheila.mrezende@hotmail.com> em 6 nov. 2013. Elaboração Cartográfica: Queiroz Júnior (2013).

Quanto à localização geográfica (Figura 1) e a divisão político-administrativa, o município de Itaberaí está localizado na Microrregião de Anápolis-007, na Mesorregião do Centro Goiano, no Noroeste Goiano, compreendido nas coordenadas geográficas $16^{\circ} 01^{\prime} 03^{\prime \prime}$ de latitude $S$ e longitude 49048"37" W.Gr (INSTITUTO BRASILEIRO DE GEOGRAFIA E ESTATÍSTICA, 2006a). Foi realizada uma revisão bibliográfica, uma pesquisa documental e uma pesquisa de campo. A princípio, o número de questionários aplicados seria de 33 , que é a quantidade de famílias nos dois assentamentos, mas, destas, foram consideradas apenas 23 que são as que mantêm a atividade leiteira como a principal atividade econômica do lote.

Para entender as particularidades e obter o maior número de informações dos dois assentamentos, foram utilizados como procedimentos técnicos: a) aplicação de questionários semiestruturados para as famílias assentadas que produzem e comercializam leite; b) entrevistas com os líderes dos dois assentamentos; c) entrevista com o representante do colegiado do Território da Cidadania do Vale do Rio Vermelho (TCVRV), para entender como as políticas públicas e os recursos têm sido alocados nos Territórios de Cidadania, e como 0 MST e a FETAEG têm se colocado no debate interno dos Colegiados Territoriais. Partiu-se do pressuposto de que a abrangência e a efetividade das políticas públicas nos Territórios da Cidadania ocorram de forma diferente das que consideram outras escalas e categorias, como municípios e estados.

\section{COMPREENDENDO AS DIFERENÇAS ENTRE A UNIDADE CAMPONESA E A UNIDADE CAPITALISTA}

Para compreender as diferenças entre a unidade camponesa e a unidade capitalista, levarse-á em consideração como as duas categorias analíticas se relacionam com os meios de produção (terra e trabalho) e como interagem com o mercado. O objetivo não é suscitar a polarização entre as duas categorias analíticas, mas entender como o capital se apodera da renda da terra no processo de circulação da mercadoria.

Aterraéum fator de produção pré-existente, tem um caráter material e simbólico; expressão de poder, de autonomia e de disputa; lugar de trabalho, 
de moradia, de extrair o lucro e a renda da terra. Dela, a unidade capitalista extrai a renda e o lucro, é considerada como terra de negócio, enquanto a unidade camponesa a considera como terra para viver e trabalhar (MARTINS, 1981). Para o camponês, a terra, a mão de obra familiar e o controle de sementes e demais insumos são elementos necessários para sua reprodução social e econômica. Para a unidade capitalista, a terra, enquanto parte da natureza, e 0 homem são explorados sem nenhuma preocupação com o equilíbrio ambiental e social, a não ser que isso seja exigência do mercado consumidor.

Explica Costa (2012) que, para Chayanov, a unidade camponesa é tanto unidade de produção quanto de consumo, tendo em vista que ela exerce as funções da esfera de produção e reprodução, simultaneamente. $\mathrm{Na}$ unidade camponesa, os membros da família representam a única mão de obra, não existindo no seu interior 0 assalariamento.

A unidade camponesa visa à reprodução familiar, produz para garantir o próprio sustento e para manter sua segurança alimentar. Buainain, Romeiro e Guanziroli (2003, p. 332) afirmam que "[...] a família é o núcleo central da produção e do controle do estabelecimento produtivo." O trabalho do camponês tem, como fim, a satisfação de suas necessidades (PONTES, 2005).

Para a unidade camponesa, o aumento da escala de produção só ocorrerá se esse aumento não tiver um efeito negativo no valor agregado por objeto de trabalho e se for financiado por recursos próprios. Sobre isso, Costa (2012, p. 97) enfatiza que

\section{[...] a escala de produção é fortemente influenciada pelo mero crescimento do número de membros da família que, exigindo um orçamento maior enquanto unidade de consumo determina um volume maior como unidade de produção.}

Já para a unidade capitalista, a escala de produção é a principal alavanca para 0 desenvolvimento agrícola. A renda está fortemente relacionada à escala de produção (PLOEG, 2008), assim, a estratégia de administração camponesa difere da capitalista.

Com relação ao mercado, a unidade camponesa vende o excedente para obter produtos e serviços externos a sua propriedade. "Enquanto uma parte é vendida, a outra é usada para a reprodução da propriedade e da família camponesa." (PLOEG, 2009, p. 19). Ao contrário, a unidade capitalista é altamente dependente e sofre influência direta das oscilações do mercado local, nacional e mundial. Para a obtenção do lucro, é necessário ampliar e manter a fatia de mercado, assim como maximizar a utilização dos fatores de produção (terra, capital, trabalho e tecnologia) no processo produtivo.

Sobre isso, Ploeg (2008, p. 137) afirma que

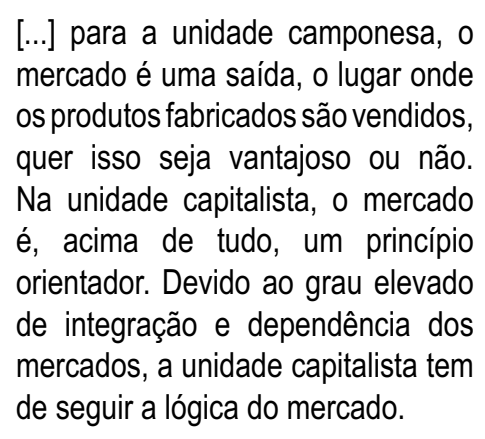

Na esfera da produção, o camponês produz as sementes na própria propriedade para serem utilizadas no processo produtivo, assim como plantam milho, sorgo e cana-de-açúcar para produção da silagem que complementa a alimentação do rebanho. Na esfera da circulação, o excedente de produção é comercializado para garantir a reprodução social da família. Ou seja, vender o que produz para comprar aquilo que não produz, sintetizada na fórmula M-D-M (mercadoria-dinheiro-mercadoria) desenvolvida por Karl Marx e que continua sendo amplamente utilizada, tanto para explicar quanto para entender a diferença entre a lógica camponesa e a lógica capitalista.

A unidade capitalista mantém uma relação de dependência com o mercado. Na esfera da produção, os insumos de produção são comprados nas empresas que estão a montante da unidade produtiva, tornando-se cada vez mais dependente 
do pacote tecnológico. Na esfera da circulação, a fórmula D-M-D' (dinheiro-mercadoria-dinheiro) norteia a produção do capitalismo, ou seja, objetivase o retorno do capital investido, viabilizando a permanência e expansão da propriedade capitalista na esfera produtiva, comercial, financeira e tecnológica.

A apropriação do trabalho, na lógica camponesa, acontece na esfera da circulação da mercadoria, enquanto que na lógica capitalista isso ocorre na esfera da produção. A acumulação de capital decorre da exploração da classe trabalhadora por parte dos proprietários dos meios de capital que se apropriam do trabalho excedente, o que é conhecido como mais-valia.

Explica Hunt (1989) que para Karl Marx, a mais-valia é nada mais do que trabalho excedente materializado. É a diferença entre D e D' (HUNT, 1989, p. 234). Nesse sentido, Oliveira (2007, p. 43) esclarece que 0

[...] trabalho excedente é a parcela do processo de trabalho que 0 trabalhador dá ao capitalista, além do trabalho necessário para adquirir os meios necessários à sua subsistência.

Dessa forma, a apropriação do valortrabalho acontece na esfera da circulação da mercadoria, na comercialização propriamente dita, que envolve desde os comerciantes de bens e serviços, os vendedores de insumos, até as agências financiadoras de crédito. Martins (1981, p. 174) afirma que "[...] o capital tende a dominar cada vez mais a produção da agricultura."

A diferenciação entre o padrão de produção camponês e o capitalista é assim sintetizada por Ploeg (2009, p. 21):

[...] a distinção entre o padrão camponês e o padrão capitalista de produção é essencial para a compreensão das dinâmicas de desenvolvimento rural. Enquanto capitalistas geram crescimento no plano de suas unidades de produção, mas com estagnação ou decréscimo do volume total de valor agregado em nível local e regional, o progresso construído pelo camponês reverte-se também em progresso para a comunidade e para a região.

Optou-se pela não distinção entre camponês e agricultor familiar, considerando que ambos possuem em comum as seguintes características: a) luta pela permanência na terra; b) utilização da mão de obra dos filhos e cônjuges na propriedade; c) preocupação em diversificar a produção para não ser tão dependente do mercado; d) manutenção da propriedade para a geração subsequente, como estratégia de reprodução familiar.

A partir dessa discussão, é possível adentrar as questões da apropriação da renda da terra pelo capital, da necessidade da organização das famílias assentadas em cooperativas e da constituição de agroindústrias que possibilitem a agregação de valor à produção e a apropriação maior da renda da atividade leiteira.

\section{APROPRIAÇÃO DA RENDA DA TERRA PELO CAPITAL E A CONSTITUIÇÃO DE COOPERATIVAS E AGROINDÚSTRIAS PARA AGREGAR VALOR AO PRODUTO}

A apropriação da renda da terra acontece sem que a unidade camponesa seja expropriada de sua terra. Ela acontece na esfera da circulação da mercadoria de origem agrícola, ou seja, a sujeição da renda da terra ao capital ocorre com a inserção da unidade camponesa no processo de comercialização.

Na medida em que o produtor preserva a propriedade da terra e nela trabalha sem o recurso do trabalho assalariado, utilizando unicamente o seu trabalho e o da sua família, ao mesmo tempo em que cresce a sua dependência em relação ao capital o que temos não é a sujeição formal do trabalho ao capital. $O$ que essa relação nos indica é outra coisa, bem distinta: 
estamos diante da sujeição da renda da terra ao capital. Esse é o processo que se observa hoje claramente em nosso país, tanto em relação à grande propriedade, quanto em relação à propriedade familiar, de tipo camponês (MARTINS, 1981, p. 175).

Para Ploeg (2008, p. 255), quando acontece a

[...] apropriação de pequenas empresas independentes por grandes grupos empresariais e do seu reordenamento total - as primeiras devem alimentar as necessidades dos últimos.

Sobre isso, Shanin $(1989$, p. 6) afirma que

[...] a entrada da exploração capitalista na agricultura familiar se expressa de fora, isto é, o capitalismo exerce a exploração por meio do sistema bancário, da produção industrial especializada.

Sem qualquer alteração aparente na sua condição, mantendo-se proprietário, mantendo 0 seu trabalho organizado com base na família, o lavrador entrega ao banco anualmente os juros dos empréstimos que faz, tendo como garantia não só os instrumentos, adquiridos com os empréstimos, mas a terra. Por esse meio, o banco extrai do lavrador a renda da terra, sem ser o proprietário dela (MARTINS, 1981, p. 176).

Da mesma forma, se estabelece a dependência do produtor em relação aos intermediários, à indústria de insumos, maquinários, assistência técnica e políticas creditícias (MARTINS, 1981). Para Oliveira (2013, p. 128), "[...] o capital cria, recria, redefine relações camponesas de produção familiar."

Portanto, a apropriação da renda da terra pode ser minimizada a partir da agregação de valor ao produto. Esse processo se dá por meio da constituição de cooperativas que possibilitariam a autonomia necessária para a reprodução social, econômica e cultural da família, pois as unidades de produção, quando operam de forma isolada, não conseguem manter essa reprodução.

Ploeg (2008, p. 207) afirma que "[...] o objetivo das cooperativas é melhorar a articulação entre a agricultura e os mercados." As cooperativas contribuem com volume, qualidade e regularidade da produção exigidos pelo mercado consumidor. A organização em cooperativas possibilita maior volume de produção, diversificação de produção, agregação de valor ao produto e redução dos custos de transação. Para o autor, os níveis de agregação de valor ao produto estão diretamente relacionados com a forma como o processo de produção agrícola é organizado.

A organização em cooperativa possibilita o acesso: a) a linhas de crédito com melhores condições de pagamento e com taxas de juros mais baixas; b) ao Programa de Aquisição de Alimentos (PAA) e Programa Nacional de Alimentação Escolar (PNAE), assim como outros circuitos curtos de comercialização; c) a cursos de qualificação e capacitação em fabricação e processamento de alimentos em agroindústrias; d) a assistência técnica e extensão rural. Esses elementos contribuem para o desenvolvimento rural.

Para Buainain, Romeiro e Guanziroli (2003, p. 339), os quatro principais condicionantes do desenvolvimento rural são:

[...] os incentivos que os produtores têm para investir e produzir, a disponibilidade de recursos, particularmente terras, água, mão de obra, capital e tecnologia, que determinam 0 potencial de produção, o acesso aos mercados, insumos, informações e serviços que influem de forma decisiva na capacidade efetiva de produção e, finalmente, as instituições, que influenciam as decisões dos agentes e inclusive sua capacidade, possibilidade e disposição para produzir.

O Ministério do Desenvolvimento Agrário, 
por meio da Secretaria da Agricultura Familiar (MDA/SAF), instituiu o Programa de Agroindústria objetivando a inclusão dos agricultores familiares no processo de agroindustrialização e comercialização da sua produção, de modo a agregar valor, gerar renda e oportunidades de trabalho no meio rural, garantindo a melhoria das condições de vida das populações beneficiadas direta e indiretamente pelo Programa (BRASIL, [2014a?]).

O Programa de Agroindústria está inserido no Programa Nacional de Fortalecimento da Agricultura Familiar (PRONAF). A origem data do ano de 1998 com a incorporação pelo PRONAF, de uma linha de crédito para investimento, denominada de Agregação de Renda a Atividade Rural (PRONAFAgregar). "Em 2003 essa linha de crédito foi renomeada para PRONAF-Agroindústria." (WESZ JÚNIOR, 2010, p. 569). "Com o objetivo de agregar renda às atividades agropecuárias." (SCHNEIDER; MATTEl; CAZELLA, 2004, p. 7).

A agroindústria familiar possibilita a agregação de valor na cadeia de produção, dando a oportunidade aos produtores de reterem uma parcela maior do lucro da atividade, e consequentemente, a melhoria na renda familiar. Essa agroindústria também diminui o circuito de comercialização, eliminando a presença de intermediários do capital comercial, convencionalmente designados como atravessadores. Trata-se de uma das estratégias para a reprodução social e econômica das famílias que residem no meio rural.

\section{CADEIA PRODUTIVA DO LEITE NO ESTADO DE GOIÁS}

A pecuária leiteira no estado é uma atividade tradicional e conta com expressiva participação de produtores de médio e pequeno porte, incluindo a produção familiar beneficiária da reforma agrária. A produção do leite possui boa liquidez, o rebanho bovino garante renda e também é considerado como reserva de valor; o retorno do investimento se dá no curto prazo, a produção (ordenha da vaca) ocorre diariamente e a receita é obtida tanto pela comercialização do leite quanto pela venda de bezerros e animais de descarte.

Em Goiás, a bacia leiteira é composta de 69.688 mil propriedades, sendo que $65 \%$ dos produtores são considerados pequenos, com área média de 125 hectares. $62 \%$ da mão de obra utilizada na atividade são oriundos do núcleo familiar. 0 rebanho leiteiro é estimado em 4 milhões de cabeças. A produção de leite de vaca cru beneficiado no ano é de 2.088.101 mil litros de leite (INSTITUTO BRASILEIRO DE GEOGRAFIA E ESTATÍSTICA, 2006b).

O leite está no início da importante cadeia produtiva do setor lácteo, que inclui a produção, industrialização de derivados como queijos e iogurtes, além dos insumos necessários. No ano de 2012, o estado de Goiás manteve a $4^{\mathrm{a}}$ posição na produção de leite com $12,66 \%$ da produção brasileira (INSTITUTO BRASILEIRO DE GEOGRAFIA E ESTATÍSTICA, 2012). De acordo com a EMATER-GO, 28\% da produção se destinam ao leite UHT (Ultra High Temperature - leite longa vida); $18 \%$ transformam-se em leite em pó e $54 \%$ são pasteurizados, transformados em queijo, manteiga, entre outros derivados. Apenas $15 \%$ são destinados ao consumo interno (FERRO, 2011).

Acadeia produtiva do leite está concentrada na Região Centro-Sul do estado de Goiás (76\% do leite produzido). 0 setor lácteo conta com mais de 160 estabelecimentos: fábricas de laticínios (96), postos de refrigeração (31), usinas de beneficiamento (28), entrepostos de laticínios (2), fábrica de produtos gordurosos (1), fábrica de coagulantes (1) e posto de recebimento (1). Esses estabelecimentos foram atraídos pelo governo por meio de incentivos fiscais e pela concessão do uso de terras para instalação de novas indústrias (OTTO; NEVES; PINTO, 2012).

Otto, Neves e Pinto (2012) enumeram alguns fatores que favorecem as atividades agropecuárias durante o ano no estado de Goiás: a) potencial hídrico; b) abundância de terras férteis; c) condições climáticas. 
Mas, assim como os outros estados produtores de leite, Goiás enfrenta diversos entraves na pecuária leiteira, como atraso tecnológico, falta de infraestrutura (precariedade das estradas que dão acesso às unidades produtivas), elevados custos de produção, que dificultam a permanência do produtor na atividade.

\section{OS ASSENTAMENTOS LUIZ ÓRIO E CARLOS MARIGUELA}

Com o objetivo de atender à demanda de dezenas de famílias acampadas na região, ocorreu a desapropriação da Fazenda São José em 2001, e da Lagoa Formosa em 2006, dando origem aos Assentamentos Carlos Mariguela e Luíz Ório. Na percepção dessas famílias, 0 assentamento rural representa a autonomia do tempo de trabalho da atividade a ser desenvolvida no lote e a constituição de novas relações sociais, pois são donos da própria terra.

O perfil socioeconômico dos assentamentos retrata uma população envelhecida, sem perspectiva de sucessão familiar e com baixa escolaridade, fatores que exercem influência sobre decisões quanto ao que produzir. A quantidade média de pessoas que residem nos lotes é de 3,27 e de 3,69 para os Assentamentos Carlos Mariguela e Luiz Ório, respectivamente. Em todos os lotes foram encontradas no mínimo 2 (duas) pessoas e no máximo 7 (sete). Ou seja, as famílias são constituídas basicamente pelo casal de idosos; em alguns casos há presença de filhos, em outros, de agregados (sogra, de pais, noras e netos). Na maioria dos lotes, os filhos já crescidos migraram para a cidade em busca de estudo e/ou trabalho. A organização interna é predominantemente conduzida pela força de trabalho familiar. 0 tamanho da família, seu crescimento e envelhecimento mantêm relação direta com 0 uso da terra e retratam o desafio de permanecer no lote e nele gerar renda para a sua reprodução social e econômica. O Quadro 1 apresenta informações sobre os dois assentamentos, objeto da pesquisa.

Os assentamentos pesquisados utilizam estratégias de reprodução familiar que vão desde as práticas de solidariedade, ajuda mútua e mutirão, ao resgate dos saberes transmitidos pelos pais no trato com a terra e com o rebanho bovino. Também utilizam a produção de silagem para complementar a alimentação do gado, evitando-se o comprometimento da rentabilidade da atividade leiteira com a compra da ração concentrada e contratação de mão de obra externa aos lotes.

\section{Quadro 1 - Objeto da Pesquisa}

\begin{tabular}{|c|c|c|}
\hline Assentamento & Carlos Mariguela & Luiz Orio \\
\hline Município & \multicolumn{2}{|c|}{ Itaberaí } \\
\hline $\begin{array}{l}\text { Quantidade de assentamentos no } \\
\text { município }\end{array}$ & \multicolumn{2}{|c|}{6 assentamentos } \\
\hline Entidade vinculada & MST & FETAEG \\
\hline $\begin{array}{l}\text { Distância do assentamento em } \\
\text { relação à sede do município de } \\
\text { Itaberaí - GO }\end{array}$ & $16 \mathrm{~km}$ & $15 \mathrm{~km}$ \\
\hline Capacidade / famílias & 12 famílias & 21famílias \\
\hline Data da criacão (ano) & 2001 & 2006 \\
\hline Área total registrada & 370,1390 ha. & 501,0005 ha. \\
\hline Área medida pelo INCRA & 379,1836 ha. & 548,0921 ha. \\
\hline Módulo Fiscal & 18,95 ha (incluida a reserva legal) & 15 ha (sem incluir a reserva legal) \\
\hline Fazenda desapropriada & \begin{tabular}{l|l} 
Lagoa Formosa &
\end{tabular} & São José \\
\hline Recursos hídricos & $\begin{array}{l}1 \text { (um) rio e } 3 \text { (três) córregos, } \\
\text { todos perenes. }\end{array}$ & $\begin{array}{l}3 \text { (três) córregos, mas apenas } 1 \text { (um) é } \\
\text { perene, e } 3 \text { (três) lagoas naturais. }\end{array}$ \\
\hline
\end{tabular}

Fonte: INSTITUTO NACIONAL DE COLONIZAÇÃO E REFORMA AGRÁRIA. Projeto de Desenvolvimento dos Assentamentos. [mensagem pessoal]. Mensagem recebida por <sheila.mrezende@hotmail.com> em 7 out. 2012. Organização dos dados: REZENDE, Sheila Marli de Melo Rezende (2013).3 
A principal atividade desenvolvida nos dois assentamentos é a produção de leite. A média da produção diária/vaca em lactação nos meses de março e abril de 2013 no Assentamento Carlos Mariguela foi de 6,3 litros, valor abaixo da média da Região Centro- Oeste (6,6 litros) e abaixo da média do Assentamento Luiz Ório que é de7,53 litros. 0 volume produzido é praticamente todo destinado à venda do leite in natura; menos de $5 \%$ é reservado para o consumo das famílias e para a fabricação de doce de leite, esse último considerado um exemplo de rearranjo do trabalho das mulheres do Assentamento Luiz Ório, visando melhorar a renda familiar. Os dois assentamentos possuem tanque de resfriamento com capacidade para aproximadamente 2.000 (dois mil) litros, adquiridos por meio do Projeto TCVRV, em conformidade com a Instrução Normativa n 51 de 18 de setembro de 2002.

De acordo com a Instrução Normativa $N^{0} 51$, no que tange à coleta, todo leite produzido não deveria sair mais "quente" (leite sem refrigeração) do lugar de produção. $O$ leite deve ir direto para um tanque resfriador de leite $e$, somente depois, ser comercializado (SILVA; BARONE; IZIDORO, 2011, p. 269, grifo dos autores).

Os dois assentamentos pesquisados estão inseridos na cadeia produtiva do leite em Itaberaí, mas essa inclusão se dá de forma subordinada. Antes da aquisição do tanque de resfriamento, o leite in natura era vendido para o leiteiro e algumas famílias produziam queijo para vender na feira de Itaberaí, mas com o tempo, desistiram da comercialização do queijo, devido às condições precárias das estradas que dificultavam o transporte, por se tratar de um produto perecível e também devido à legislação sanitária.

O preço praticado no mês de abril de 2013 era de $R \$ 0,98$ por litro. A renda da atividade leiteira mal cobre os custos da produção, as famílias assentadas operam com margem de lucro reduzida. Estão sujeitas à tesoura de preços, uma vez que se encontram entre os fornecedores de insumos e as poucas opções existentes para vender sua produção. Herrera e outros (2005) explicam que Alberto Passos Guimarães foi responsável pela noção de tesoura de preços, que retrata a situação de subordinação dos produtores a montante à indústria fornecedora de insumos, máquinas e equipamentos (D1) e também a jusante à indústria processadora que fixa preços e quantidades a ser demandada, ou seja, o produtor fica diretamente subordinado à indústria.

A atividade leiteira proporciona uma renda contínua, mas é necessário o gerenciamento dos custos de produção, pois o pequeno produtor é tomador de preço, ou seja, o preço é dado pelo mercado, o foco é a eficiência na gestão para se obter melhor rentabilidade. Oliveira (2004, p. 42) revela que

[...] o capital sujeitou a renda da terra gerada pelos camponeses à sua lógica, ou seja, se está diante da metamorfose da renda da terra em capital.

Na pesquisa, verificou-se a necessidade de melhoria da condição e da qualidade da produção do leite, para que se possa produzir o leite barriga mole para que essa produção seja inserida na merenda escolar, no PAA, PNAE e no mercado, diminuindo a participação do laticínio na comercialização do leite.

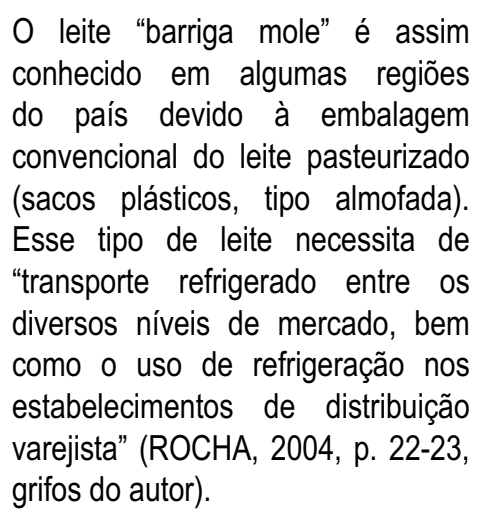

A industrialização do leite ainda não é possivel porque os municípios do TCVRV não contam com inspeção municipal. A legislação fitosanitária como está estabelecida para os produtos de origem 
animal não permite que pequenos produtores industrializem minimamente a produção. Prezotto e Nascimento (2013, p. 7) esclarecem que

$$
\begin{aligned}
& \text { [...] existem três modalidades } \\
& \text { de inspeção da produção/ } \\
& \text { processamento de produtos } \\
& \text { de origem animal: a) os } \\
& \text { estabelecimentos que pretendem } \\
& \text { comercializar seus produtos } \\
& \text { em qualquer local do Brasil } \\
& \text { devem se registrar no Serviço } \\
& \text { de Inspeção Federal (SIF); b) os } \\
& \text { estabelecimentos que pretendem } \\
& \text { comercializar seus produtos } \\
& \text { apenas no território de seu Estado } \\
& \text { devem se registrar no Serviço de } \\
& \text { Inspeção Estadual (SIE); c) os } \\
& \text { estabelecimentos que pretendem } \\
& \text { comercializar seus produtos apenas } \\
& \text { no território de seu município devem } \\
& \text { se registrar no Serviço de Inspeção } \\
& \text { Municipal (SIM). }
\end{aligned}
$$

Sobre essa questão, em 2006, o MDA regulamentou o Sistema Único de Atenção à Sanidade Agropecuária (SUASA) visando adequar a inspeção sanitária dos produtos industrializados nas pequenas agroindústrias familiares para facilitar a comercialização desses produtos em todo o território nacional, e assim, gerar novos postos de trabalho e melhorar a renda das famílias envolvidas no processo produtivo (BRASIL, [2014b]). Nesse sentido, é necessário o debate sobre a efetividade do SUASA, pois não houve muito avanço em sua proposta inicial.

Quanto à natureza da produção do leite, normalmente ela está relacionada ao caráter penoso do trabalho, pois requer tempo e trabalho ininterrupto. No caso dos dois assentamentos pesquisados, o trabalho diário está relacionado tanto com o manejo do rebanho quanto com a ordenha manual. Como consequência, os filhos migram para a cidade em busca de emprego e renda, pois não têm interesse em continuar com esse modelo de produção rudimentar, que requer trabalho árduo e retorno financeiro muito aquém das suas necessidades e aspirações juvenis.

Sobre a migração dos filhos para a cidade em busca de estudo e/ou trabalho, Buainain, Romeiro e Guanziroli (2003, p. 332) afirmam que o
[...] esvaziamento é associado às novas e melhores oportunidades oferecidas aos filhos dos agricultores nos centros urbanos ou à falta de desenvolvimento local do meio rural.

A migração dos filhos para a cidade em busca de emprego e renda pode, ao mesmo tempo, ser um entrave para a sucessão familiar e uma renda extra, já que, se os filhos tivessem permanecido no lote, o trabalho não seria remunerado.

Identificou-se na pesquisa que tanto 0 MST quanto a FETAEG exerceram importante papel na luta e conquista da terra, mas o grande desafio a ser enfrentado é a permanência nela, ou seja, a luta na terra. Os estudos de Oliveira (2010, p. 201, grifo do autor) revelam que

[...] a luta na terra tem se constituído ainda no principal desafio a ser superado, uma vez que no momento em que a terra é conquistada 0 movimento perde grande parte da influência sobre esses novos agricultores.

Faz-se necessária a criação de estratégias para a manutenção das famílias assentadas para que os lotes sejam produtivos e rentáveis o suficiente para garantir a reprodução social, econômica e cultural dessas famílias.

Acredita-se que a ampliação, aprimoramento e consolidação de políticas públicas de desenvolvimento rural, compatíveis com a dinâmica da produção familiar, se constituem num caminho factível de possibilitar tal reprodução socioeconômica. Os resultados iniciais alcançados pelo Programa de Aquisição de Alimentos e Programa Nacional de Alimentação Escolar são elucidativos a este respeito, conforme têm demonstrado estudos diagnósticos desses programas, conforme evidenciado por Delgado (2013).

\section{CONCLUSÃO}

A proposta da pesquisa realizada no âmbito do mestrado era analisar as formas de 
organização e as estratégias de comercialização que contribuam para a inserção das famílias assentadas no mercado do leite. Para tanto, foi considerada a organização social, política, econômica e tecnológica existente nos assentamentos pesquisados, assim como a influência dessas 4 (quatro) variáveis no grau de inserção no mercado do leite.

Quanto à organização social: a) organização interna é predominantemente conduzida pela força de trabalho familiar; b) organização coletiva é baseada nas relações por afinidades provenientes da fase de acampamento que continuaram depois que as famílias foram assentadas e elas convivem de forma harmoniosa.

Quanto à organização política, a luta pela terra é um processo histórico de resistência. O MST e a Via Campesina foram instituições importantes na conquista da terra, por meio da mobilização nacional e das reivindicações para que o governo federal desapropriasse latifúndios improdutivos e os transformassem em assentamentos rurais. $\mathrm{Na}$ percepção das famílias assentadas, tanto o MST quanto a FETAEG foram importantes na luta pela terra e estiveram mais presentes na fase de acampamento, mas, o mesmo não acontece com a luta constante para permanecer na terra. A luta na terra é enfrentada com a união, a ajuda mútua e a colaboração das famílias, visando o bem-estar social.

Quanto à organização tecnológica: a) os dois assentamentos pesquisados possuem tanque de resfriamento em conformidade com a Instrução Normativa $n^{\circ} 51$, que redesenhou 0 modo de se produzir, armazenar, coletar e transportar o leite no Brasil; b) apresentam baixos níveis de investimento (melhorar a alimentação do gado leiteiro); c) ordenha manual; d) sistema de produção rudimentar com o desmame do bezerro acontecendo de forma tardia (entre seis meses e um ano); e) apresentam dificuldade para obter maquinário (trator) para 0 preparo do solo.

Quanto à organização econômica, a inserção ao mercado faz parte de uma estratégia para reprodução social, econômica e cultural da família. Os dois assentamentos estão inseridos na cadeia produtiva do leite em Itaberaí, mas essa inclusão se dá de forma subordinada. Na percepção das famílias assentadas, a presença do laticínio como um canal de comercialização é considerada positiva, isso porque visualizam apenas o benefício da renda regular e mensal. Do ponto de vista da premissa teórica é um ponto negativo, pois a parcela maior do lucro da atividade leiteira fica em poder dos laticínios. A renda da atividade leiteira, que chega ao final do mês, também contribui para subordinar as famílias assentadas, que não conseguem avançar em termos de produtividade e rentabilidade.

Conclui-se que, quando analisada economicamente, a atividade leiteira não tem autonomia e domínio sobre sua renda, pois, além da mão de obra familiar, o capital, a estrutura física e o rebanho bovino são colocados à disposição da empresa capitalista, o laticínio. Ou seja, da forma como a atividade leiteira está estruturada, quem ganha mais é a agroindústria.

Conclui-se, também, que nos assentamentos pesquisados 0 processo de subsunção da renda da terra pelo capital tem se mantido, em que pese as ações das lideranças no âmbito do colegiado territorial do TCVRV.

Para minimizar esse problema, recomendase a constituição de agroindústrias familiares e a estruturação da cooperativa para que garantam melhorias tais como: a) elevação dos índices de produtividade e de rentabilidade da atividade leiteira; b) o beneficiamento do leite de acordo com a atual legislação sanitária; c) a diversificação da produção. Os objetivos dessas medidas são: minimizar a dependência de um único produto, acessar novos mercados como o PAA e PNAE, por fim, podendo gerar um aumento da renda proveniente do lote como resultado dessa nova forma de se fazer agricultura.

\section{REFERÊNCIAS}

BRASIL. Ministério do Desenvolvimento Agrário. Programas Agroindustriais. Portal da Cidadania, 
Brasília, DF, [2014a?]. Disponível em:<http://portal. mda.gov.br/portal/saf/programas/agroindustrias>. Acesso em: 5 jun. 2014.

Programas Suasa. Portal da Cidadania, Brasília, DF, [2014b?]. Disponível em:<http://portal.mda.gov.br/portal/saf/programas/ suasa>. Acesso em: 5 maio 2014.

BUAINAIN, Antônio Márcio; ROMEIRO, Ademar; GUANZIROLI, Carlos. Agricultura familiar e o novo mundo rural. Sociologias, Porto Alegre, ano 5, n. 10, p. 312-347, jul./dez. 2003.

COSTA, Francisco de Assis. Economia camponesa nas fronteiras do capitalismo: teoria e prática nos EUA e na Amazônia Brasileira. Belém: Ed. NAEA, 2012.

DELGADO, Guilherme. Relatório Final de Avaliação do PAA. [S. L.: s. n.], 2013. Mimeo.

FERRO, Jusus Xavier. Pecuária leiteira emprega 220 mil pessoas em Goiás. Goiânia: EMATER-GO, 2011. Disponivel em:<http://www.emater.go.gov. br/w/1328>. Acesso em: 6 maio 2014.

HERRERA, Vânia Érica et al. A Competitividade da Agroindústria Sucroalcooleira do Brasil e o Mercado Internacional: barreiras e oportunidades. In: CONGRESSO DA SOBER, 43., 2005, Ribeirão Preto, SP. Anais eletrônicos... Ribeirão Preto, SP, 2005. Disponível em:<http://www.sober.org.br/ palestra/2/1020.pdf>. Acesso em: 14 ago. 2014.

HUNT, E. K; História do pensamento econômico. 10. ed. Traduzido por José Ricardo Brandão Azevedo. Rio de Janeiro: Editora Campus, 1989.

INSTITUTO BRASILEIRO DE GEOGRAFIA E ESTATÍSTICA. Cidades@: Goiás. Rio de Janeiro, 2006a. Disponivel em:<http://cidades.ibge.gov.br/ xtras/temas.php?lang $=\&$ codmun $=521040$ \&idtema $=3$ \&search=goias $\mid$ itaberai|censo-agropecuario-2006>. Acesso em: 6 maio 2014.

Censo Agropecuário de 2006. Rio de Janeiro, 2006b. Disponível em: <http://www.ibge. gov.br/homeestatistica/economia/agropecuaria/ censoagro/2006/agropecuario.pdf>. Acesso em: 31 julho 2012.

C Censo Demográfico de 2010. Rio de Janeiro, 2010. Disponível em:<http://cidades.ibge.gov.br/xtras/perfil. php?lang $=\&$ codmun $=521040 \&$ search $=$ goias $\mid$ itaberai $>$. Acesso em: 14 nov. 2012.

Pesquisa Pecuária Municipal, 2012. Rio de Janeiro, 2012. Disponível em:<ftp://ftp.ibge.gov. br/Producao_Pecuaria/Producao_da_Pecuaria_ Municipal/2012/tabelas_pdf/tab06.pdf>. Acesso em: 1 nov. 2013.

INSTITUTO NACIONAL DE COLONIZAÇÃO E REFORMAAGRÁRIA. Projeto de Desenvolvimento dos Assentamentos. [mensagem pessoal]. Mensagem recebida por <sheila.mrezende@hotmail. com> em 7 out. 2012.

Shape dos Assentamentos. [mensagem pessoal]. Mensagem recebida por<sheila. mrezende@hotmail.com> em 6 nov. 2013.

MARTINS, José de Souza. Os camponeses e a política no Brasil. Petrópolis, RJ: Vozes, 1981.

MEDINA, Gabriel da Silva; CAMARGO, Ricardo de Siqueira. Relatório analítico do Território do Vale do Rio Vermelho, Goiás. Brasília, DF: MDA, [20-?]. Disponivel em:<http://sit.mda.gov.br/download/ra/ ra067.pdf> Acesso em: 1 set. 2013.

MOREIRA, Roberto José. Agricultura familiar: processos sociais e competitividade. Rio de Janeiro: Editora Mauad, 1999.

OLIVEIRA, Adriano Rodrigues. 0 associativismo na região do Pontal do Paranapanema-SP: limites e possibilidades para o desenvolvimento rural. 2010. $209 \mathrm{f}$. Tese (Doutorado em Geografia) - Faculdade de Ciências e Tecnologia, Programa de Pós-Graduação em Geografia, Universidade Estadual Paulista, Presidente Prudente, SP, 2010.

Ariovaldo Umbelino de. Barbárie e modernidade: as transformações no campo e 0 agronegócio no Brasil. In: STÉDILE, João Pedro 
(Org.). A questão agrária no Brasil: o debate na década de 2000. São Paulo: Editora Expressão Popular, 2013. p. 103-172.

Geografia agrária: perspectivas no início do século XXI. In: OLIVEIRA, Ariovaldo Umbelino. MARQUES, Marta Inez Medeiros (Orgs.). 0 campo no século XXI: território de vida, de luta e de construção da justiça social. São Paulo: Editora Paz e Terra, 2004. p. 29-70.

Modo capitalista de produção, agricultura e reforma agrária. São Paulo: FFLCH, 2007. Disponivel em:<http://www.geografia.fflch.usp.br/ graduacao/apoio/Apoio/Apoio_Valeria/Pdf/Livro_ari. pdf>. Acesso em: 14 mar. 2012.

OTTO, Igor Montenegro Celestino; NEVES, Marcos Fava; PINTO, Mariun Junqueira Alves. Cadeia produtiva de lácteos. Goiânia: FIEG, 2012.

PAULINO, Eliane Tomiasi. Políticas territoriais e questão agrária: da teoria à intervenção. In: SAQUET, Marcos Aurélio; SANTOS, Roselí Alves dos (Orgs.). Geografia agrária, território e desenvolvimento. São Paulo: Editora Expressão Popular, 2010. p. 107-130.

PLOEG, Jan Douwe Van der. Camponeses e impérios alimentares: lutas por autonomia e sustentabilidade na era da globalização. 1. ed. Traduzido por Rita Pereira. Porto Alegre: Ed. UFRGS, 2008.

Sete teses sobre a agricultura camponesa. In: PETERSEN, Paulo (Org.). Agricultura familiar camponesa na construção do futuro. Rio de Janeiro: AS-PTA, 2009. Disponível em:<http://www.agriculturesnetwork. org/magazines/brazil/especial/sete-teses-sobre-aagricultura-camponesa/at_download/article_pdf>. Acesso em: 9 jun. 2014.

PONTES, Beatriz Maria Soares. A organização da unidade econômica camponesa: alguns aspectos do pensamento de Chayanov e de Marx. Revista NERA, Presidente Prudente, ano 8, n. 7, p. 35-47, jul./dez. 2005.
PREZOTTO, Leomar Luiz (Elaboração); NASCIMENTO, Mário Augusto Ribas do (Orgs). Cartilha sobre inspeção sanitária de estabelecimentos que processam alimentos. Brasília, DF: MDA; Ministério da Agricultura, Pecuária e Abastecimento, 2013. Disponível em:<http://seminariossuasa.com.br/images/ inspecao_estabelecimentos.pdf $>$. Acesso em: 1 maio 2014.

QUEIROZ JÚNIOR, Vilson Sousa. Elaboração Catográfica. [mensagem pessoal]. Mensagem recebida por<sheila.mrezende@hotmail.com> em 3 ago. 2013.

ROCHA, Giulianna Lara. Influência do tratamento térmico no valor nutricional do leite fluido. 2004. Monografia (Trabalho de Conclusão de Curso) - Universidade Católica de Goiás, Goiânia/ GO, 2004. Disponível em:<http://professor.ucg.br/ SiteDocente/admin/arquivosUpload/8930/material/ TCC-Giulianna $\% 20-\% 20 I N F L U \%$ C3\%8ANCIA $\% 20$ DO\%20TRATAMENTO\%20T\%C3\%89RMICO\%20 NO $\% 20$ VALOR $\% 20$ NUTRICIONAL $\% 20$ DO $\% 20$ LEITE\%20FLUIDO.pdf>. Acesso em: 29 abr. 2014.

SCHNEIDER, Sérgio; MATTEI, Lauro; CAZELLA, Ademir Antônio. Histórico, caracterização e dinâmica recente do PRONAF - Programa Nacional de Fortalecimento da Agricultura Familiar. In:

SILVA, Marcelo Kunrath; MARQUES, Paulo Eduardo Moruzzi. (Orgs). Políticas Públicas e participação social no Brasil Rural. Porto Alegre: Ed. UFRGS, 2004, p. 21-50. Disponível em:<http://www.ufrgs.br/ pgdr/arquivos/394.pdf> acesso em 14 de agosto de 2014.

SHANIN, Theodor. Chayanov e a questão do campesinato. Textos de Estudo, Porto Alegre, v. 7, n. 89, 1989.

SILVA, Martha Esthela; BARONE, Luís Antônio; IZIDORO, Lais Túbero. A produção leiteira em assentamentos de reformaagrária: renda, organização e resistência. Retratos de assentamentos: Revista do Núcleo de Pesquisa e Documentação Rural (Nupedor), Araraquara, SP, v. 14, n. 1, p. 265-282, 2011. 
WESZ JÚNIOR, Valdemar João. Política pública de agroindustrialização na agricultura familiar: uma análise do PRONAF-Agroindústria. Revista de Economia e Sociologia Rural, Piracicaba, SP, v. 48, n. 4, p. 567-596, out./dez. 2010. Disponível em: <http://www.scielo.br/pdf/resr/v48n4/a04v48n4.pdf>. Acesso em: 14 ago. 2014.

NOTA

${ }^{1}$ Dados da Dissertação: REZENDE, Sheila Marli de Melo. Comercialização do leite dos assentamentos Carlos Mariguela e Luiz Ório no município de Itaberaí-GO: análise comparativa. 2014. 128 f. Dissertação (Mestrado em Agronegócio) - Programa de Pós-graduação em Agronegócio, Universidade Federal de Goiás, Goiânia, Goiás, 2014. Disponível:<http://repositorio.bc.ufg.br/tede/handle/tde/2941> Acesso em: 26 de novembro de 2014.

\section{Sheila Marli de Melo Rezende}

Economista

Mestra em Agronegócio pela Universidade Federal de Goiás (UFG)

Economista do Centro de Ciências Sociais, Saúde e Tecnologia da Universidade Federal do Maranhão (CCSST/UFMA)

Email: sheila.mrezende@hotmail.com

\section{Dinalva Donizete Ribeiro}

Geógrafa

Doutora em Geografia pela Universidade Federal Fluminense (UFF)

Professora Associada da Escola de Agronomia (EA) da Universidade Federal de Goiás (UFG)

Email: dinalvadr@gmail.com

\section{Universidade Federal do Maranhão - UFMA}

Cidade Universitária - Av. dos Portugueses, 1966, Baganga, São Luís, MA

CEP: $65080-805$

Universidade Federal de Goiás - UFG

Campus Samambaia - Rodovia Goiânia / Nova Veneza, Km 0,

Goiânia, GO

CEP: $74690-900$ 